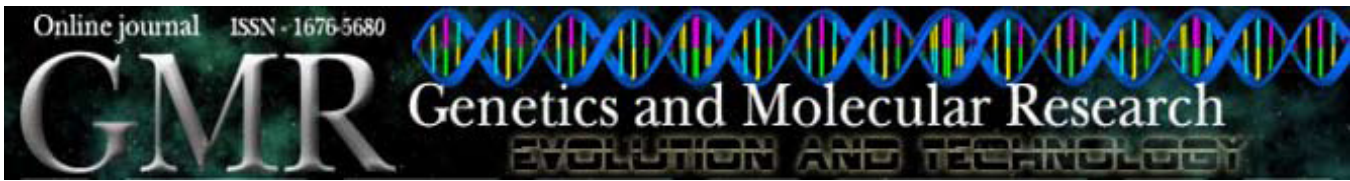

\title{
A genetic analysis of post-weaning feedlot performance and profitability in Bonsmara cattle
}

\author{
R.R. van der Westhuizen ${ }^{1}$, J. van der Westhuizen ${ }^{1}$ and S.J. Schoeman ${ }^{2}$ \\ ${ }^{1}$ ARC-Animal Production Institute, Irene, South Africa \\ ${ }^{2}$ Department of Animal Sciences, University of Stellenbosch, \\ Matieland, South Africa
}

Corresponding author: R.R. van der Westhuizen

E-mail: bobbie@arc.agric.za

Genet. Mol. Res. 8 (1): 179-196 (2009)

Received October 11, 2008

Accepted November 20, 2008

Published February 25, 2009

\begin{abstract}
The aim of this study was to identify factors influencing profitability in a feedlot environment and to estimate genetic parameters for and between a feedlot profit function and productive traits measured in growth tests. The heritability estimate of 0.36 for feedlot profitability shows that this trait is genetically inherited and that it can be selected for. The genetic correlations between feedlot profitability and production and efficiency varied from negligible to high. The genetic correlation estimate of -0.92 between feed conversion ratio and feedlot profitability is largely due to the part-whole relationship between these two traits. Consequently, a multiple regression equation was developed to estimate a feed intake value for all performance-tested Bonsmara bulls, which were group fed and whose feed intakes were unknown. These predicted feed intake values enabled the calculation of a postweaning growth or feedlot profitability value for all tested bulls, even where individual feed intakes were unknown. Subsequently, a feedlot profitability value for each bull was calculated in a favorable economic environment, an average economic environment and in an unfavorable economic environment. The high Pearson and Spearman correlations between the estimate breeding values based on the average economic environment and the other two environments suggested that the aver-
\end{abstract}


age economic environment could be used to calculate estimate breeding values for feedlot profitability. It is therefore not necessary to change the carcass, weaned calf or feed price on a regular basis to allow for possible re-rankings based on estimate breeding values.

Key words: Beef cattle; Post-weaning growth; Growth efficiency; Feedlot profitability

\section{INTRODUCTION}

During the last couple of years and with the rapid development of computer hardware, animal breeding and selection decisions have developed into a complex field of research. Today, beef breeders are faced with a challenge to decide which traits to include in their selection objectives and which to exclude.

It is important for a breeder to include all traits of economic importance related to his selection objectives, but at the same time include as few traits as possible. It is a well-known fact that the rate of genetic change decreases as the number of traits in the selection objective increases. Therefore, biological traits (e.g., feed intake) are only worth consideration in a selection objective if they are associated with an expense or income (profitability). Water is a major "biological" input into animal production systems, yet is seldom considered in efficiency studies because of its relatively low costs.

The cost of feed is an important variable affecting the profitability of beef production. Ferrell and Jenkins (1984), Urich et al. (1984), van Oijen et al. (1992), and Johnston (2002) stated that a cow-herd has been estimated to consume $56-70 \%$ of the energy required for beef production. Slaughter stock often consumes expensive feed, particularly those finished on high concentrate feedlot diets. Manipulation of the environment and cattle management can be used to reduce feed costs. It has also been known for several decades that feed intake and measures of feed efficiency are heritable in beef cattle (Johnston, 2002).

In South Africa, more than $70 \%$ of all beef consumed is the result of cattle intensively fed in a feedlot. It is known and agreed upon that feed intake and growth are the two most important economic components when calculating profitability (biological efficiency) in a feedlot or in growth tests. The inclusion of feed intake and growth information in a beef cattle production selection objective will facilitate genetic improvement in efficiency and profitability of any beef enterprise. The inclusion of feed intake and growth rate in selection decisions, however, requires appropriate measurements of these two traits.

Various productive, reproductive and efficiency traits are currently measured in South Africa's Agricultural Research Council's (ARC) Beef Cattle Improvement Scheme. Young bulls are measured for growth, efficiency and body measurements in centralized or in on-farm growth tests. Individual feed intake and weight gain are recorded on a weekly basis in the centralized growth tests. Due to the availability of feed intake and weight gain of bulls tested in the centralized growth tests, it is possible to calculate a post-weaning or feedlot profitability value for each bull tested.

A second question that arises is to what extent do price fluctuations influence a postweaning (feedlot) profitability value. The economic environment changes over time due to the fact that feed and carcass prices change on a regular basis and can show extreme fluctua- 
tions. This must be taken into consideration with the estimation of an economical feedlot or post-weaning growth profit value because, when the feed price decreases and the carcass price stays the same or even increases, animals that consume feed above average feed intake, with a lower feed conversion ratio (FCR), could become more profitable, while an animal with a good FCR but consuming less feed could be less profitable. It could be expected that the ranking of the animals, based on their profitability breeding values (estimating breeding values, EBVs), could change.

The aim of this study was to develop a method for determining a feedlot profitability value for each performance bull tested, tested either in a centralized or an on-farm growth test (through the use of a regression equation) and to estimate genetic (co)-variances for and between feedlot profitability and other production and efficiency traits. With fluctuations in feed and carcass prices, a second aim was to determine if a different feedlot profit EBV is required for different market situations.

\section{MATERIAL AND METHODS}

Data analyzed in this study were collected from the South Africa's ARC national database. Records of Bonsmara bulls, tested in centralized growth tests and in an on-farm growth test between 1975 and 2001, were used.

In the prediction of a feedlot or post-weaning growth profitability value, feed intake was required in the calculation. Young weaner bull calves were sent to one of the ARC central testing stations where individual feed intake and weights were recorded on a weekly basis. Body measurements were also measured at the onset and completion of the test. On arrival, bulls went through a four-week adaptation period to gradually adapt to the feedlot diet. These growth tests were originally 20 weeks long. In 1990, they were shortened to a 16-week test period, and in 1999 to a 12-week testing period as a result of recommendations from the study of Archer and Bergh (2000). In South Africa, however, the majority of bulls tested in a postweaning growth test were tested in an on-farm growth test, where bulls were group fed, and individual feed intakes were unknown. Therefore, of the 82,778 Bonsmara bulls that were performance tested only $11,835(14 \%)$ were tested in a centralized growth test of the ARC, while the majority $(70,943$ or $86 \%)$ were tested in an on-farm growth test where individual feed intakes are unknown. Because of this, two data sets were used in this study. The first data set only included bulls tested in the centralized tests while the second data set also included bulls tested in on-farm growth tests. The first data set consisted of the individual feed intake and weights of 10,318 bulls taken on a weekly basis. After appropriate editing, the data set for the estimation of variance components was reduced to 6738 recorded bulls.

Efficiency and productive traits measured in the centralized growth tests are feed intake and body weight on a weekly basis as well as shoulder height (SHD) at the end of the testing period. An average daily gain (ADG) value is then calculated for each bull at the end of the testing period. Individual FCR were derived for each bull as the total feed intake divided by the weight gain during the testing period. Therefore, FCR is the quantity of feed consumed by the animal in order to gain a kilogram in body weight. Weaning weights (WW) for these bulls were obtained from the ARC pre-weaning recording program.

Subsequently, using all the available recorded information, a feedlot profitability value or post-weaning growth value expressed in South African currency (Rand) was calculated 
for each bull as if the tested bull was fed under feedlot conditions and sold to an abattoir. The following equation was used to calculate a feedlot profitability (FP) value for each bull tested in a centralized growth test:

$$
\begin{gathered}
\mathrm{FP}=[\mathrm{Uwt} \times \mathrm{CPr} / \mathrm{kg}]-[(\mathrm{BWt} \times \mathrm{BWtPr} / \mathrm{kg})+ \\
(\mathrm{FI} \times \mathrm{FPr} / \mathrm{kg})+((\mathrm{BWt} \times \mathrm{BWtPr} / \mathrm{kg}) \times((\mathrm{Br} / 365) \times \mathrm{TL})+(\mathrm{VC})]
\end{gathered}
$$

where Uwt $=$ slaughter weight $(55 \%$ of final weight $) ; \mathrm{CPr} / \mathrm{kg}=$ price per kilogram carcass weight; $\mathrm{BWt}=$ body weight on commencement of the test; $\mathrm{BWtPr} / \mathrm{kg}=$ live weight price per kilogram for weaners; $\mathrm{FI}=$ feed intake; $\mathrm{FPr} / \mathrm{kg}=$ feed price per kilogram; $\mathrm{Br}=$ interest rate; $\mathrm{TL}=$ test length; $\mathrm{VC}=$ veterinary costs.

Due to the unavailability of carcass measurements, the following assumptions were made in order to calculate a feedlot profitability value:

- Live weight weaner calf price at R8.25 per kilogram (the initial weight at onset of the growth test is used)

- A3-carcass price of R12.35 per kilogram (it is assumed that all bulls are classified as A3-carcass grade (animals younger than 2 years with 3-5 $\mathrm{mm}$ of subcutaneous fat))

- Feed cost set at R0.90 per kilogram

- Interest rate on an overdraft account at $14 \%$

- It is assumed that all slaughter costs are covered by the fifth quarter (skin, intestines and head)

- Slaughter percentage of $55 \%$ ( $55 \%$ of the weight of the bull on completion of growth test)

- Veterinary costs of R3.50 per week (approximately R60 for a 4-week adaptation period and a 12-week test).

The effects of all non-genetic sources of variation on the traits were estimated by the PROC GLM procedure of SAS Institute (2000). Only effects significant at P $<0.001$ were subsequently included in the final models fitted. Non-genetic sources that were included in the models for WW were the linear and quadratic regressions on the age of the dam, the linear and quadratic regression on the age of the animal at weaning and the contemporary group for weaning weights (herd, weaning date and treatment code) as a fixed effect (1246 levels). For ADG, only the linear regression of the age of the dam and the contemporary group fixed effect for the growth test (test center, test year, test phase, and test number) were included in the model (514 levels). For SHD, the linear and quadratic regression of the age of the animal at the end of the growth test, the linear regression of the age of the dam and the contemporary group fixed effect for the growth test were included as non-genetic sources. For FCR and FP, the linear regression of the age of the animal at the end of the growth test and age of dam were included with the contemporary group effect as fixed. All the above-mentioned non-genetic sources were significant $(\mathrm{P}<$ 0.001 ) and were therefore included in both models. Table 1 gives a summary of the different models used. 


\begin{tabular}{|c|c|c|c|c|c|c|c|}
\hline Factor & Effect & Levels & WW & $\mathrm{ADG}$ & SHD & FCR & FP \\
\hline Age & $\mathrm{C}$ & & & & $\mathrm{X}$ & $X$ & $\mathrm{X}$ \\
\hline Age $x$ age & $\mathrm{C}$ & & & & $\mathrm{X}$ & & \\
\hline Dam age & $\mathrm{C}$ & & $\mathrm{X}$ & $\mathrm{X}$ & $\mathrm{X}$ & $\mathrm{X}$ & $\mathrm{X}$ \\
\hline Dam age $\mathrm{x}$ age & $\mathrm{C}$ & & $\mathrm{X}$ & & & & \\
\hline Weaning age & $\mathrm{C}$ & & $\mathrm{X}$ & & & & \\
\hline Weaning age $\mathrm{x}$ age & $\mathrm{C}$ & & $\mathrm{X}$ & & & & \\
\hline Growth test contemporary group & $\mathrm{F}$ & 514 & & $\mathrm{X}$ & $\mathrm{X}$ & $\mathrm{X}$ & $\mathrm{X}$ \\
\hline Weaning contemporary group & $\mathrm{F}$ & 1246 & $\mathrm{X}$ & & & & \\
\hline
\end{tabular}

$\mathrm{WW}=$ weaning weight; $\mathrm{ADG}=$ average daily gain; $\mathrm{SHD}=$ shoulder height $\mathrm{FCR}=$ feed conversion ratio; $\mathrm{FP}=$ feedlot profitability; Age = age of the animal at the end of the growth test; Dam age = age of the dam at the end of test; Weaning age = age of the animal at weaning; $\mathrm{C}=$ covariate; $\mathrm{F}=$ fixed effect; Growth test contemporary group = test center, test year, test phase, and test number; Weaning contemporary group = herd, weaning date and treatment code.

Variance components, heritabilities and genetic correlations for and between WW, ADG, SHD, FCR, and FP were estimated by using multitrait restricted maximum likelihood procedures, using the VCE package developed by Groeneveld (1994).

The following equation was used for analysis:

$$
\mathrm{y}=\mathrm{Xb}+\mathrm{Za}+\mathrm{e}
$$

where $y=$ vector of the observations for the $i^{\text {th }}$ trait; $b=$ vector of fixed effects for the $i^{\text {th }}$ trait; $\mathrm{a}=$ vector of random animal effects for the $\mathrm{i}^{\text {th }}$ trait; $\mathrm{e}=$ vector of random residual effects for the $\mathrm{i}^{\text {th }}$ trait; $\mathrm{X}$ and $\mathrm{Z}=$ incidence matrices relating records of the $\mathrm{i}^{\text {th }}$ trait to fixed and random animal effects, respectively.

Subsequent estimation of variance components, as well as breeding values for each animal in the pedigree file, was predicted for the different traits under investigation. The genetic trend (average breeding values of all animals born per year) for FP and FCR was derived through the use of these predicted breeding values obtained above.

As mentioned previously, the majority (86\%) of performance-tested Bonsmara bulls were group fed in an on-farm growth test. Traits measured in the on-farm growth tests were initial weight (weight of the bull at the beginning of the testing period), final weight (the weight of the bull at the end of the growth test period), and SHD. Once again, an ADG value as well as a Kleiber ratio estimate (where the Kleiber ratio estimate is the ADG divided by the bull's metabolic weight) were calculated for each bull at the end of the testing period.

In order to predict a feed intake value for on-farm tested bulls (where individual feed intakes are unknown), a step-wise regression, using the PROC REG procedure of SAS Institute (2000), was performed on centralized growth test data, where individual feed intakes were known. All traits measured in an on-farm and centralized growth tests were initially included in the step-wise regression.

With the help of these predicted feed intake values, a feedlot or post-weaning FP could be calculated for each bull, tested in an on-farm growth test (Equation 1).

Genetic variance components estimated in Equation 2 for bulls tested in the centralized growth test were used to estimate breeding values for FP for each bull tested in an on-farm growth test, using the multitrait animal model as was discussed. 
To address the problem of the fluctuation in weaner live weight, carcass and feed prices and the effect they have on FP, the monthly average weaner, A3-carcass and feed prices were obtained from the South African Feedlot Association (SAFA), South African Meat Industry Company's (SAMIC) web pages and from the central testing station of the ARC-Irene from January 1998 to June 2002, respectively. These prices were then used to calculate a ratio between meat and feed prices over years to identify the most profitable, as well as the less profitable environment in which to produce beef from the feedlot.

Estimated breeding values for FP for each animal in the pedigree file were predicted in an unfavorable economic environment, an average economical environment and in a favorable economic environment for beef production. The PROC CORR procedure of SAS Institute (2000) was then used to obtain Pearson and Spearman correlations between phenotypic and estimated breeding values of FP, calculated in the three different economic environment scenarios.

\section{RESULTS AND DISCUSSION}

Figure 1 is a presentation of the average body weight from week one up to and including week 20 for all bulls tested in Phase C.

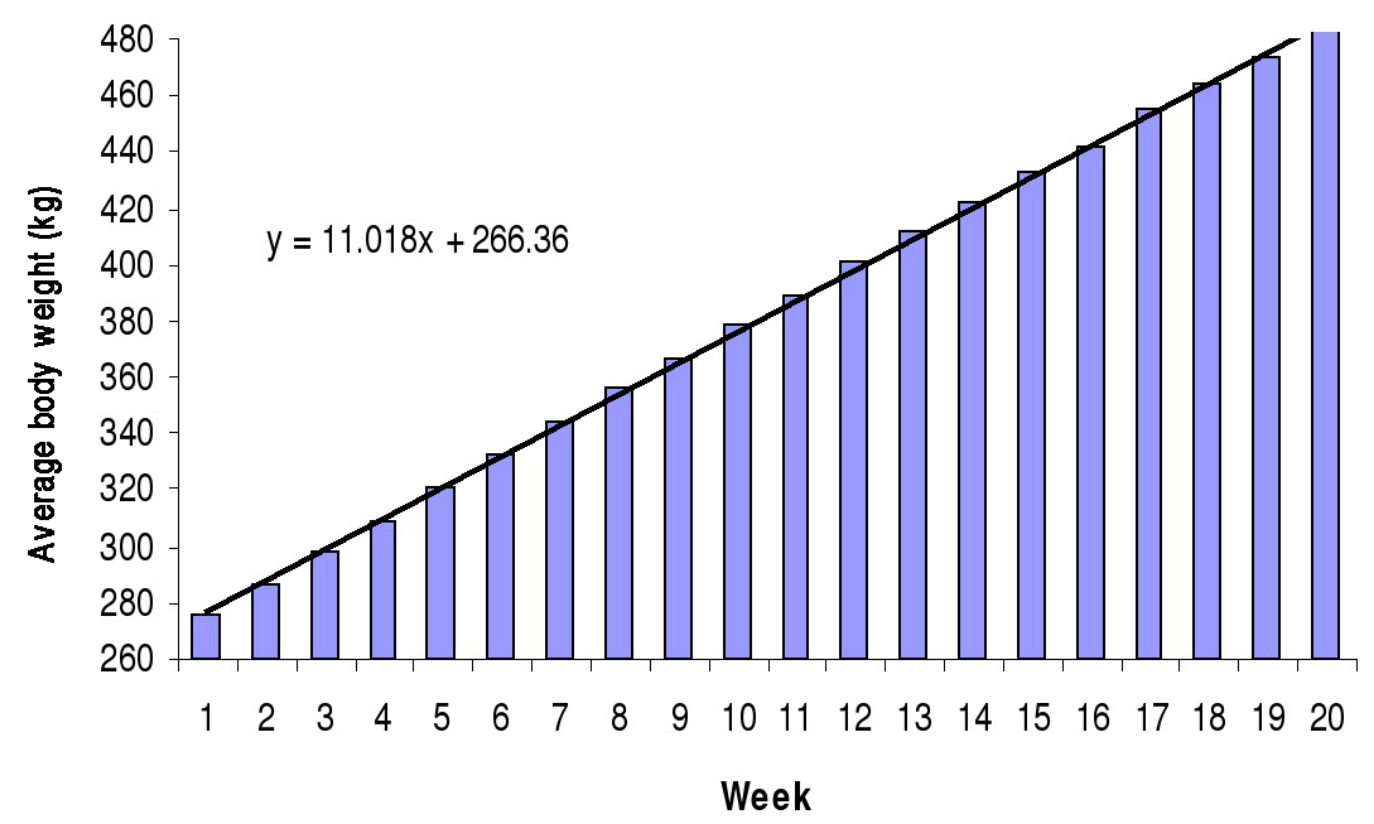

Figure 1. Average weekly body weight of centralized tested bulls (kg).

As a result of the variation in test length, weeks 1 to 12 represent 10,318 bulls, weeks 13 to 16, 8830 bulls, and weeks 17 to 20, 3934 bulls. From the graph, it is apparent 
that the bulls' body weights increased linearly over time, with an average of $11.0 \mathrm{~kg}$ per week. The scale used is in fairly large increments, therefore smaller differences will not be as apparent.

Figure 2 indicates the average weekly gain. From Figure 2, it is apparent that the average weekly gain increased from week 1 to week 8 with an average of $12.02 \mathrm{~kg}$ per week, where afterward it decreased with a sudden drop at week 16 and increased again from weeks 17 to 20. This decline in weekly gain up to week 16 is the result of differences in diet compositions used in the different test periods over years. In the 20-week growth test the diet contained $357.5 \mathrm{~g}$ roughage per $\mathrm{kg}$ of feed, whereas the 16-week and 12-week growth tests feed rations contained only $200 \mathrm{~g}$ of roughage per $\mathrm{kg}$ of feed. The average weekly feed intake of the 16week test was also higher than either the 12- or 20 -week test periods and is the reason for the increase in the average weekly gain.

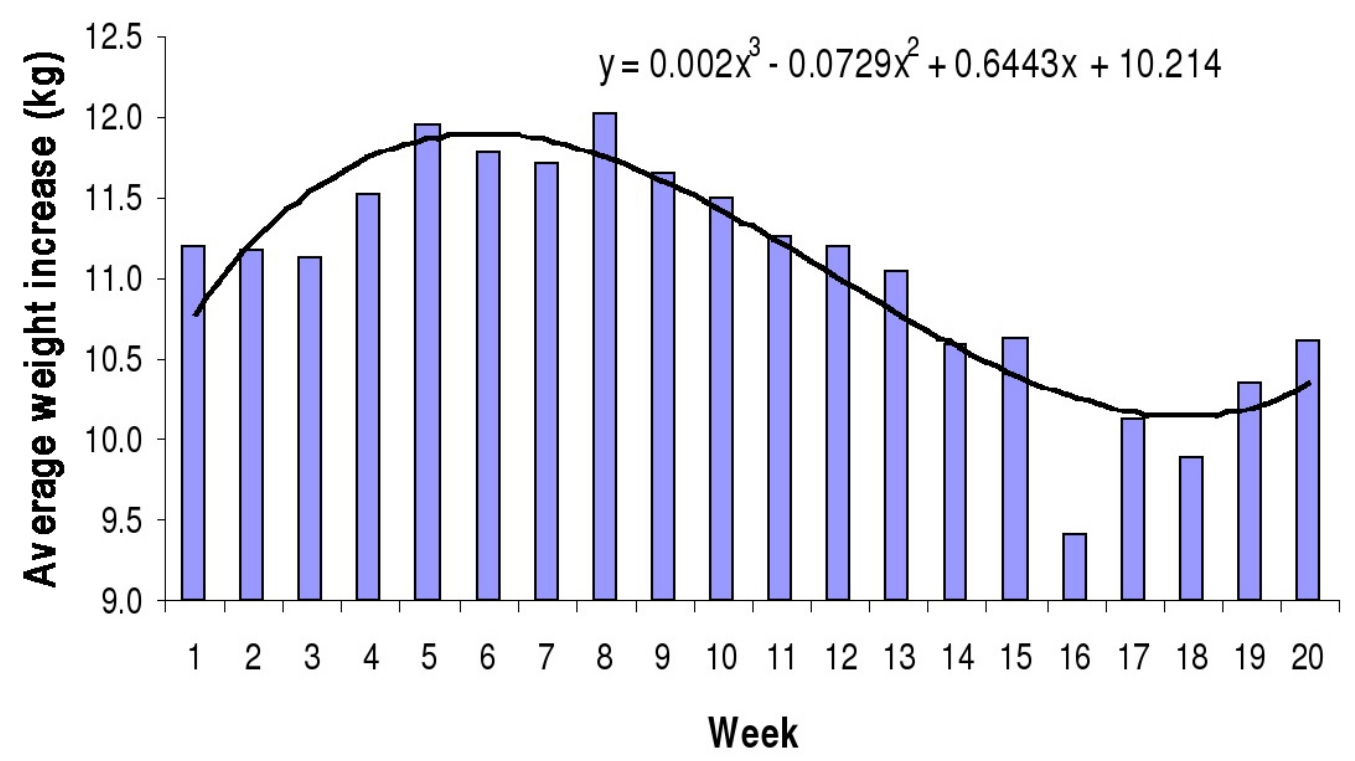

Figure 2. Average weekly weight gain $(\mathrm{kg})$.

Average feed intake (Figure 3) gradually increased from week one (58.5 kg/week) up to and including week $14(79.8 \mathrm{~kg} /$ week $)$, where afterward the average feed intake declined slightly and then stabilized over weeks 18, 19 and 20 (77.2 kg/week). The average FCR (Figure 4) showed a gradual increase from week one (6.3 $\mathrm{kg}$ feed/ $\mathrm{kg}$ body weight increase) up to and including week 16 (9.4 kg feed/ $\mathrm{kg}$ body weight increase), where afterward it improved slightly. Once again, this pattern is the result of different feed diets used in the different test periods over years, especially, the differences in the percentage roughage. The poor average increase in FCR of $9.4 \mathrm{~kg}$ feed per $\mathrm{kg}$ body weight at week 16 is also the result of the higher percentage roughage in the diet. 


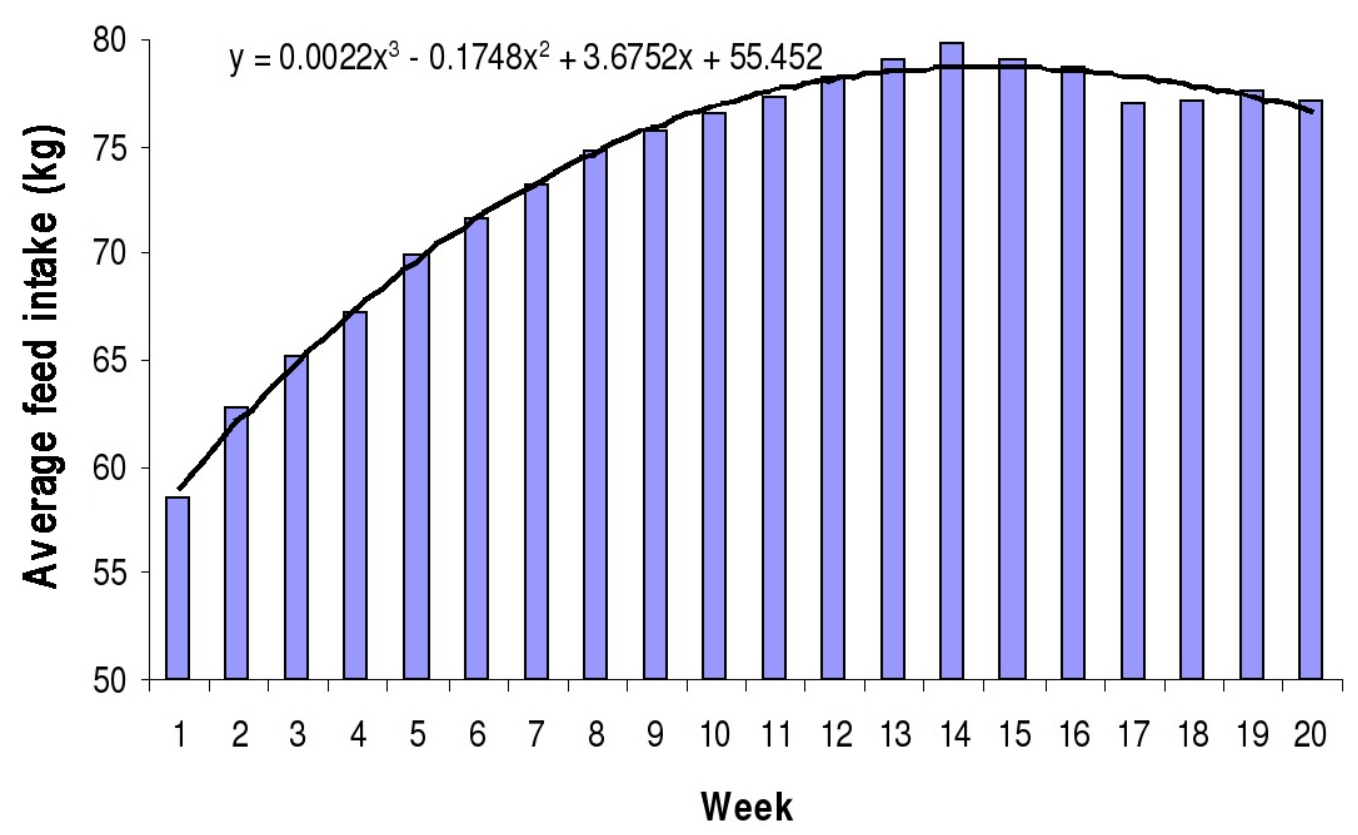

Figure 3. Average weekly feed intake (kg).

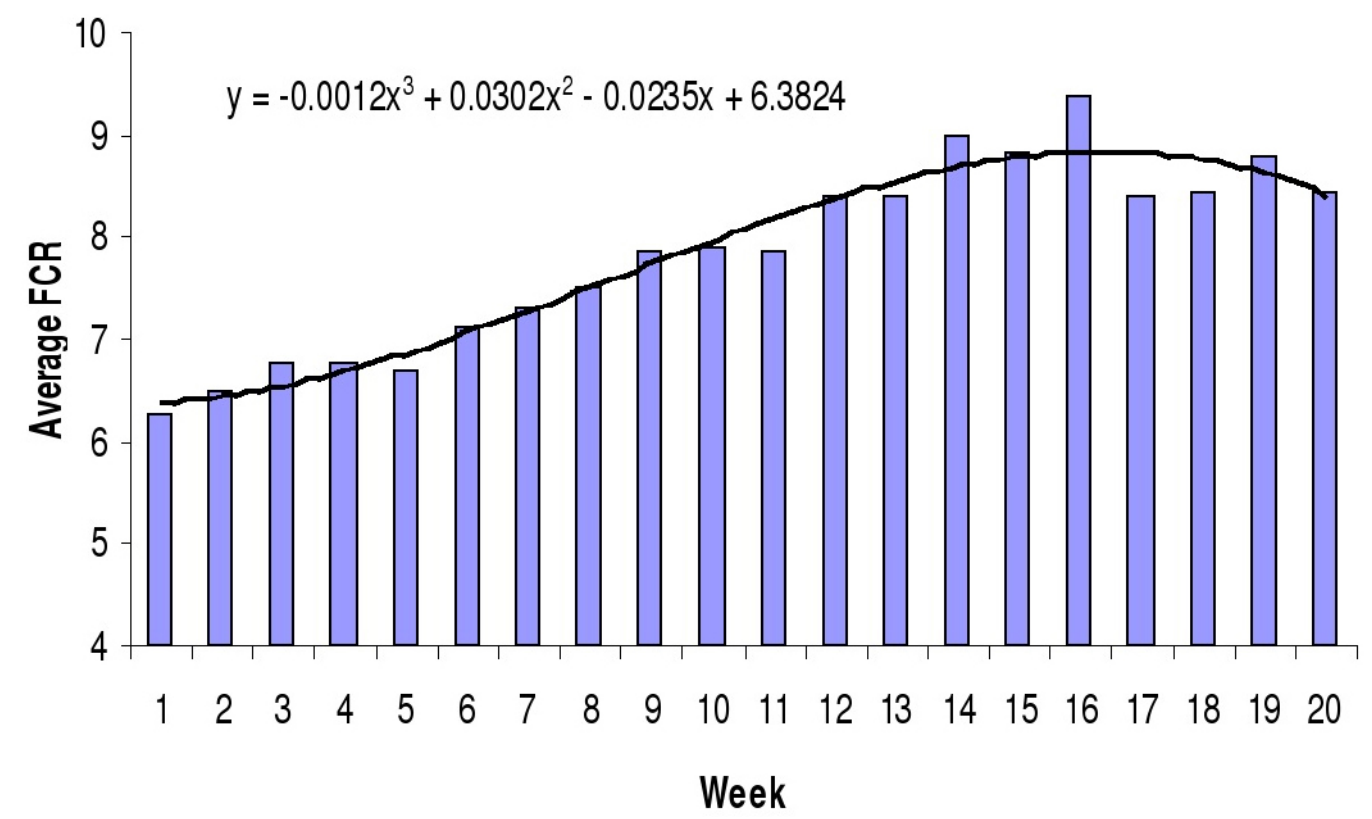

Figure 4. Average weekly FCR (feed conversion ratio). 
Figure 5 shows the average profit per week. Profit increased linearly from week one (from a loss of R141.51) to week ten (with a profit on R105.81), where afterward it decreased sharply to week twenty showing a loss of R555.47. From Figure 5, it is clear that average profit reached a maximum at week ten. At the end of week ten the bulls had been fed for 98 days (a 28-day adaptation period and 70 days in the test). This is in agreement with the average feeding period of 100 days used by the feedlots, as well as the optimum test length of 70-84 days (after a 1-week adaptation period) recommended by Archer and Bergh (2000).

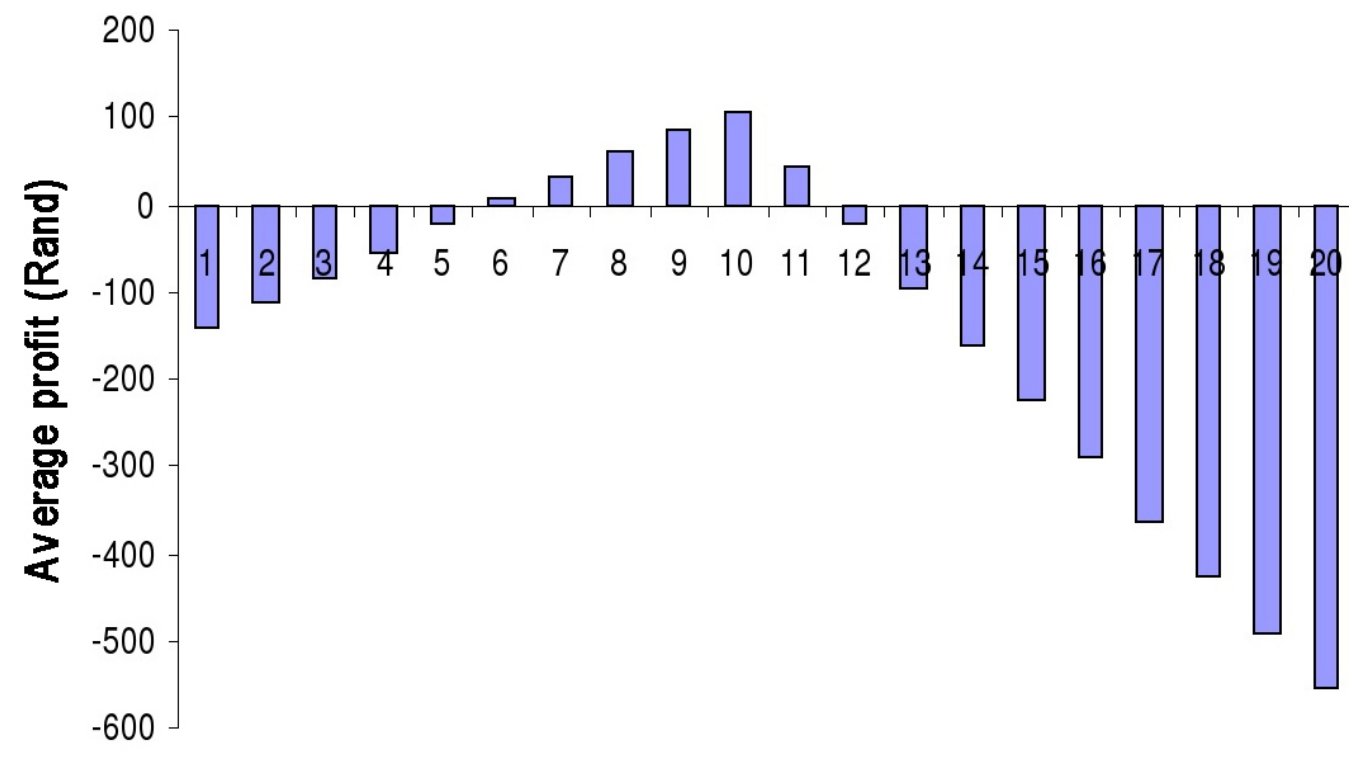

\section{Week}

Figure 5. Average weekly feedlot profit.

Table 2 presents the general statistics for the different traits and covariates, included in the different models.

\begin{tabular}{l} 
Table 2. General statistics for the different traits and covariances in models. \\
\hline Trait/covariance \\
\hline WW $(\mathrm{kg})$
\end{tabular}

$\mathrm{WW}=$ weaning weight; $\mathrm{ADG}=$ average daily gain; $\mathrm{SHD}=$ shoulder height; $\mathrm{FCR}=$ feed conversion ratio; $\mathrm{FP}=$ feedlot profitability; Age = age of the animal at the end of the growth test; Dam age = age of the dam at the end of test; Weaning age $=$ age of the animal at weaning. 
The average (standard deviation, SD) age of the animals at weaning was 205 (23.3) days with an average WW of $234 \mathrm{~kg}(30.7 \mathrm{~kg})$. This is $20 \mathrm{~kg}$ heavier than the average 205 days adjusted WW of the Bonsmara breed (males and females) for the birth years 1993 to 1998 (Anonymous, 1999). The average age of the animals at the end of the growth test was 358 days with an SD of 26.6 days, reflecting the age limits set on young bulls participating in centralized growth tests. The age of the dams varied from 1 year and 10 months (669 days) to 16 years, with an average of 6 years of age. The mean of FCR $(6.4 \pm 0.81)$ corresponds with the mean FCR of $6.5 \pm 0.9$ obtained by Arthur et al. (2001). The less profitable animal in the growth tests suffered a loss of R824.78 while the most profitable animal achieved a profit of R494.36 under the assumptions mentioned earlier. The average FP was a loss of R223.93 ( $\pm \mathrm{R} 141.28)$. This is the result of many animals being fed for a period longer than optimal. It also indicates that a feedlot has to select the most profitable animals to be able to make a profit under these circumstances.

Table 3 presents the heritability and genetic correlation estimates (with standard errors) for and between the different traits under investigation.

\begin{tabular}{|c|c|c|c|c|c|}
\hline & WW & $\mathrm{ADG}$ & SHD & FCR & FP \\
\hline WW & $0.30 \pm 0.02$ & $0.29 \pm 0.04$ & $0.54 \pm 0.03$ & $-0.04 \pm 0.05$ & $-0.22 \pm 0.05$ \\
\hline ADG & & $0.36 \pm 0.01$ & $0.48 \pm 0.02$ & $-0.69 \pm 0.01$ & $0.65 \pm 0.01$ \\
\hline SHD & & & $0.51 \pm 0.02$ & $-0.23 \pm 0.02$ & $0.10 \pm 0.02$ \\
\hline FCR & & & & $0.34 \pm 0.01$ & $-0.92 \pm 0.01$ \\
\hline FP & & & & & $0.36 \pm 0.01$ \\
\hline
\end{tabular}

The heritability for and genetic correlation estimates between WW, ADG, SHD, and FCR are on the same order as those mentioned by Anonymous (1999) and Koots et al. (1994a,b).

The heritability estimate of 0.36 for FP shows that this trait is genetically inherited and that it can be selected for. The genetic correlations between FP and the other traits varied from negligible to high. The genetic correlation of 0.10 between SHD and FP indicates that SHD is of no real value in selecting for FP. The genetic correlation of -0.22 between WW and FP could be because of a compensatory growth effect. An animal showing compensatory growth will have a better FCR, and therefore, it will grow more efficiently and be more profitable. High WW also results in higher purchase prices for a feedlot.

The high genetic correlation of ADG and FCR with FP was expected, as these two traits are the main contributors to the variation in FP. The genetic correlation of -0.92 between FCR and FP is a result of this part-whole relationship. This was expected because for each kilogram less feed an animal consumes in order to gain a kilogram in body weight, the more profitable the animal becomes. Therefore, one can select indirectly for FP through the use of FCR as selection criterion, though with a smaller correlated response. The relative correlated response (as discussed in Falconer and Mackay (1996)) in FP was 0.87 if selection was based on FCR. This indicates that only $87 \%$ genetic improvement will be achieved in FP if one selects directly for FCR compared to direct selection for FP. 
Figures 6 and 7 represent the genetic trends for FCR and FP for the Bonsmara growthtested animals, respectively.

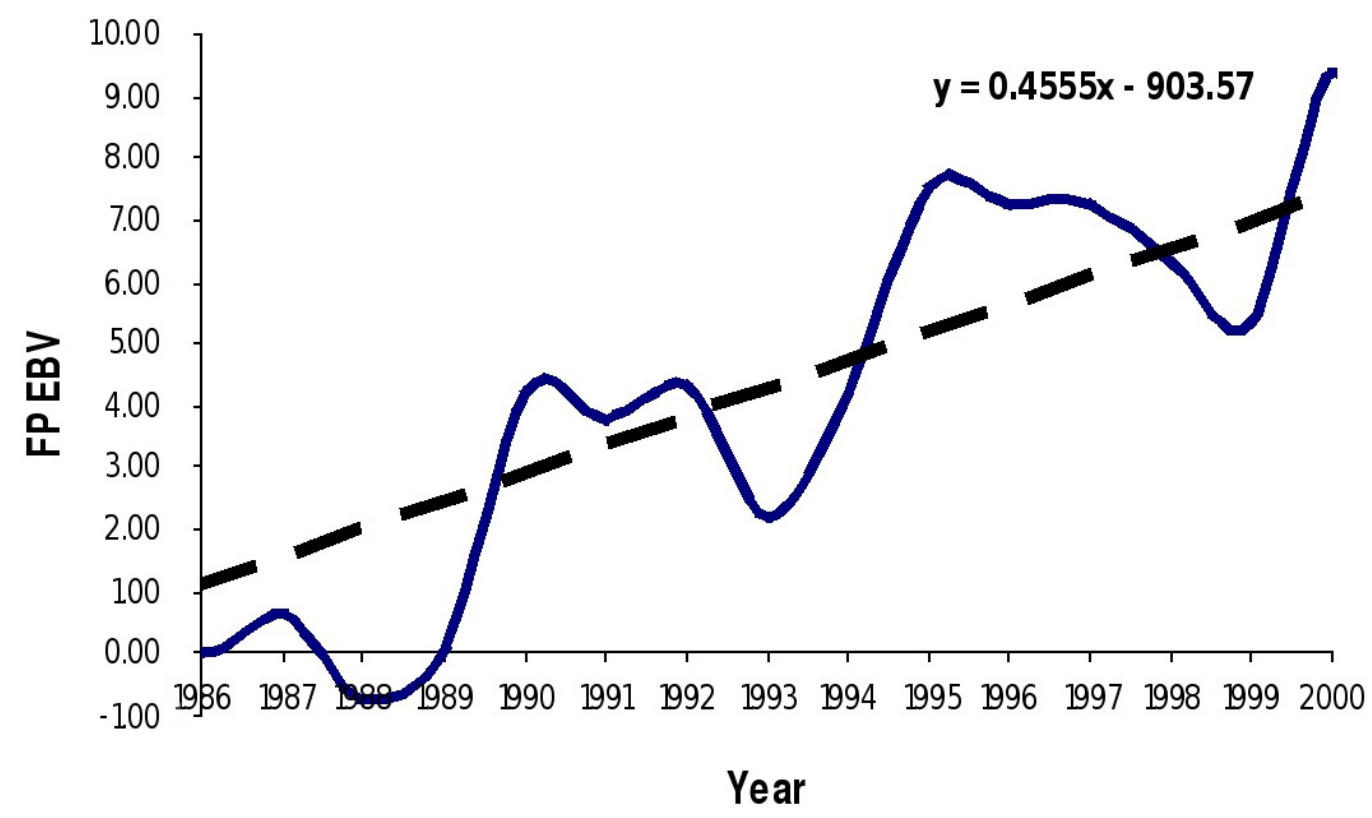

Figure 6. Genetic trend of feedlot profit (FP) for the Bonsmara Phase $\mathrm{C}$ animals. EBV = estimated breeding values.

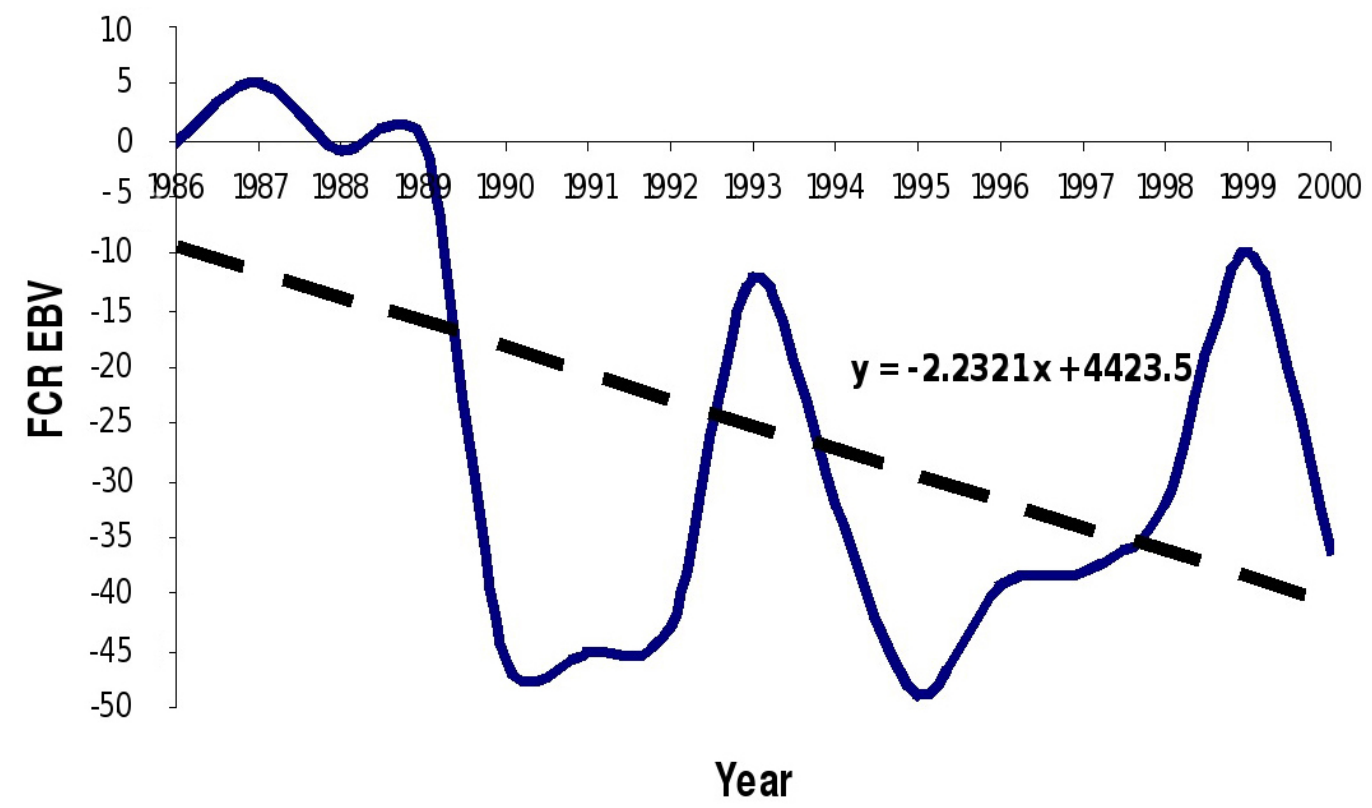

Figure 7. Genetic trend of feed conversion ratio (FCR) for the Bonsmara Phase $\mathrm{C}$ animals. EBV = estimated breeding values. 
From these figures, it is clear from the pattern of the genetic trends for FCR and FP that there was a reduction in FCR with a corresponding improvement in FP.

Table 4 presents the final multiple stepwise regression model used to predict feed intakes of centralized tested animals.

Table 4. Final multiple stepwise regression model to predict feed intake values in centralized tested animals.

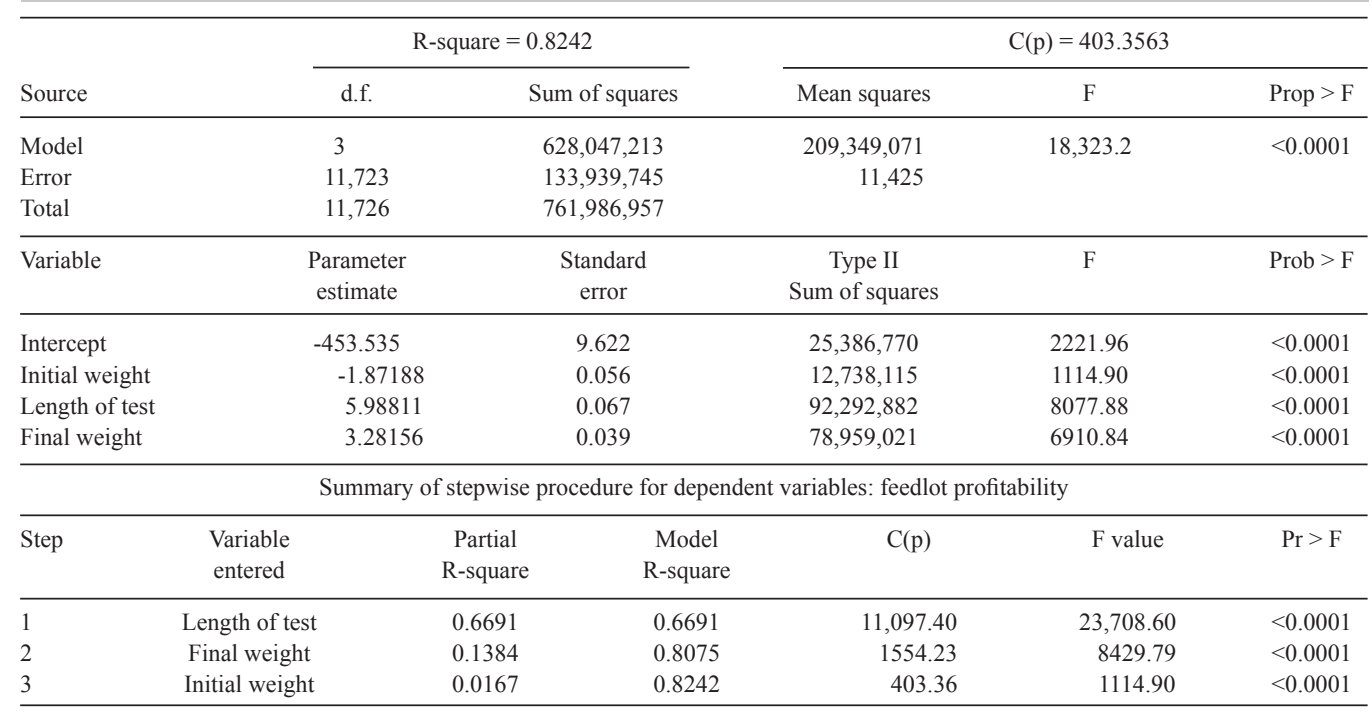

From Table 4, it is clear that the length of the testing period in days accounts for most of the variation (67\%) in feed intake, even in the saturated model, where the inter-relationships among variables are taken into account (partial $\mathrm{R}^{2}$ ). The second and third most important variables are final and initial weights, which account for 14 and 2\%, respectively, for the variation in feed intake. The contributions of ADG, Kleiber ratio and the age of the animal were lower than $0.2 \%$ and were excluded. From this analysis, it is possible to draft a regression model to predict a feed intake value for each animal where all variables, included in the regression, are known. The model to predict a feed intake value for Bonsmara centralized tested animals was as follows (only variables included at $\mathrm{P}<0.01$; total $\mathrm{R}^{2}=0.82$ ):

$$
\begin{gathered}
\text { Feed intake }=(-1.872 \times \text { initial weight })+ \\
(5.988 \times \text { test length })+(3.282 \times \text { final weight })+453.535
\end{gathered}
$$

The Pearson correlation between the measured feed intake values and the predicted feed intake values, predicted through the use of Equation 3, for all Bonsmara bulls tested in a centralized growth test is 0.91 . This high correlation indicates that the predicted feed intake values can be used as an indication of what the observed feed intake will be.

Equation 3 was then used to predict a feed intake value for all on-farm growth tested bulls. By the use of this regression Equation 3, one can compare feed intake values between centralized and on-farm growth tested animals, although they were on different diets. These 
feed intakes were then used in Equation 1 to derive predicted profitability values (FP) for each on-farm growth tested Bonsmara bull.

Table 5 presents the general statistics for all bulls tested in a centralized or in an onfarm growth test from 1975 to 2001 for test length (days), feed intake (kg), predicted feed intakes (kg), FPs, and EBV for FP.

Table 5. General statistics for centralized and on-farm growth tested animals as well as for pedigree animals' test length (days), feed intake, predicted feed intakes, feedlot profitability (FP), and the estimated breeding values (EBV) for FP.

\begin{tabular}{|c|c|c|c|c|c|c|c|c|}
\hline Variable & $\mathrm{N}$ & Minimum & Maximum & Mean & Variance & SD & SEM & $\begin{array}{l}\text { Coefficient of } \\
\text { variation }(\%)\end{array}$ \\
\hline \multicolumn{9}{|c|}{ Centralized tested bulls } \\
\hline Test length & 9278 & 84 & 140 & 118.16 & 416.35 & 20.40 & 0.188 & 17.270 \\
\hline Feed intake & 9278 & 433 & 2030 & 1231.53 & $64,932.12$ & 254.82 & 2.34 & 20.690 \\
\hline \multicolumn{9}{|l|}{ Predicted } \\
\hline Feed intake & 9278 & 521 & 1842 & 1232.02 & $53,715.17$ & 231.77 & 2.13 & 18.810 \\
\hline FP & 9278 & -1188.27 & 387.99 & -407.26 & $28,188.76$ & 167.90 & 1.55 & -41.225 \\
\hline EBV & 9278 & -165.96 & 215.43 & 16.24 & 1624.67 & 40.31 & 0.40 & 248.21 \\
\hline \multicolumn{9}{|c|}{ On-farm tested bulls } \\
\hline Test length & 67,160 & 84 & 365 & 143.14 & 1143.96 & 33.82 & 0.135 & 23.630 \\
\hline \multicolumn{9}{|l|}{ Predicted } \\
\hline Feed intake & 67,160 & 494 & 3208 & 1320.10 & $71,041.62$ & 266.54 & 1.07 & 20.190 \\
\hline FP & 67,160 & -2462.45 & 294.52 & -575.76 & $62,922.90$ & 250.84 & 0.94 & -43.567 \\
\hline EBV & 67,160 & -135.84 & 238.44 & 15.69 & 1147.08 & 33.89 & 0.13 & 215.91 \\
\hline \multicolumn{9}{|c|}{ Pedigree Animals ${ }^{\#}$} \\
\hline EBV & 79,204 & -165.96 & 238.44 & 11.54 & 935.22 & 30.58 & 0.08 & 265.11 \\
\hline
\end{tabular}

Pedigree animals are parents of tested bulls without own performance records.

It can be seen from Table 5 that the maximum test length of the centralized and onfarm growth tests differs by a large extent (140 days for the centralized test and 365 days for the on-farm growth tests). This results in an increase in the average feeding (testing) period of on-farm growth tests of 25 days compared to the centralized tests. This is the reason for the higher average predicted feed intakes of $98.6 \mathrm{~kg}$ for on-farm growth tested bulls, compared to the average feed intakes of $1232 \mathrm{~kg}$ for centralized tested bulls. The average feed intake of the centralized tested bulls does not differ significantly from the average predicted feed intakes for these centralized tested bulls of $1232 \mathrm{~kg}$. The higher feed intakes are then the reason for a lower average profitability or FP (average loss of R575.76) calculated for bulls tested on on-farm growth tests (this was also expected because farmers only send selected bulls to be tested in a centralized growth test while the rest will be submitted to an on-farm growth test on the farm).

This more conservative approach using regression could limit the variance around mean values. This could be the reason for the standard error of the mean being lower in the on-farm growth tests than in the centralized growth tests.

The mean, SD (variance) and coefficient of variation of the EBVs of the pedigreed animals were lower than those of the on-farm and/or centralized growth tested animals. The reason for this could be because pedigreed animals do not have their own measurements and only receive an EBV from their relatives. Best linear unbiased prediction estimates for these animals an even more conservative EBV closer to the mean of their parents' EBVs. 
Figure 8 represents the genetic trend for FP for all bulls tested in the growth tests (Phase C or D) from 1986 to 2001. It was decided by the Bonsmara Breed Society to use 1986 as a base year for all genetic traits. The average EBVs of animals born in 1986 was thus set at zero.

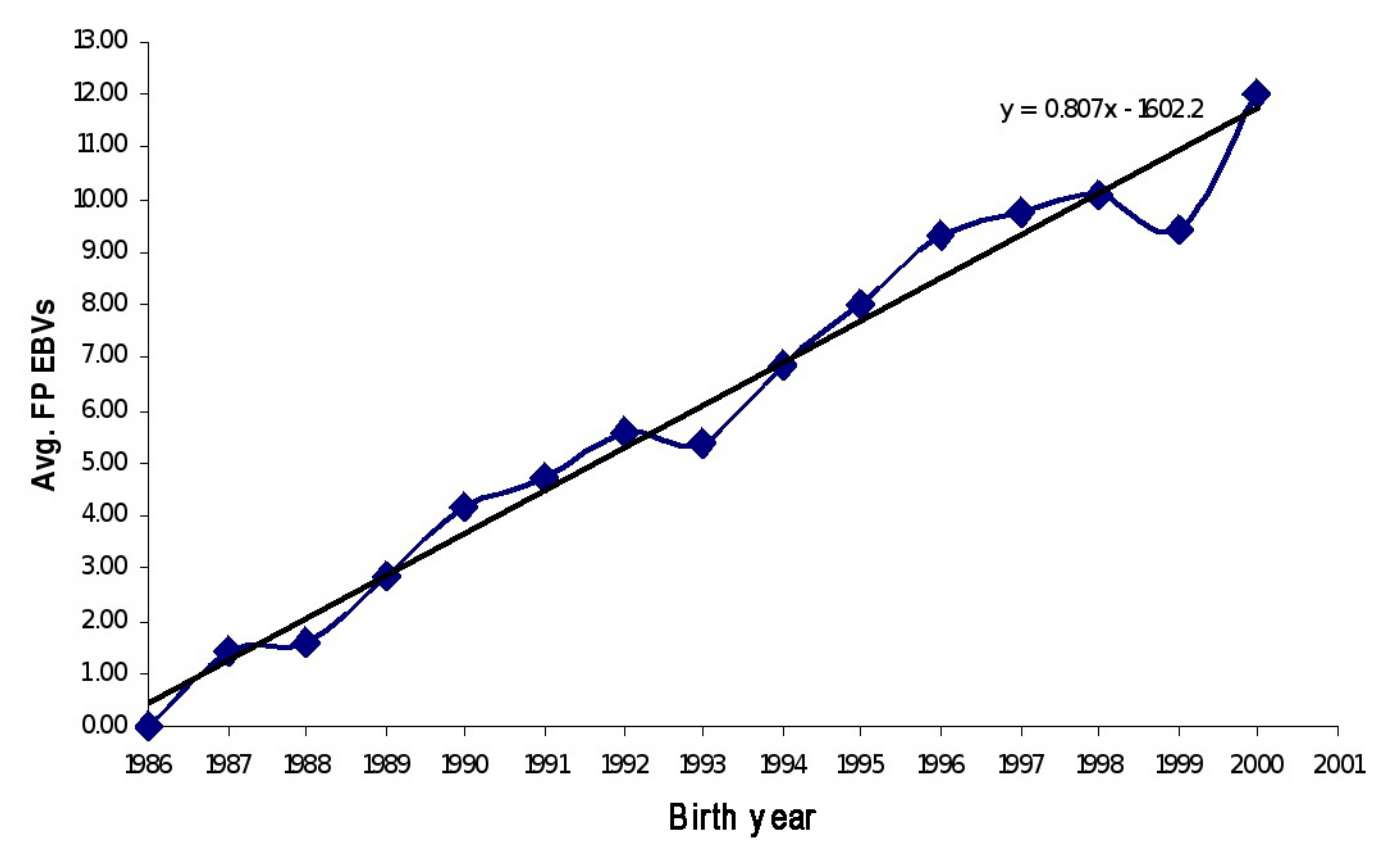

Figure 8. Genetic trend for feedlot profitability (FP) for all performance tested bulls tested in a Phase C or D growth test of the South Africa's Agricultural Research Council. EBV = estimated breeding values.

Figure 8 shows a genetic improvement in FP from 1986 until 2001. This improvement can be explained by the high genetic correlation between feed efficiency traits and profitability (FP) and also selection for feed efficiency over years. The genetic trend also shows that FP is a trait that can be effectively selected for. Direct selection could even lead to more rapid progress as the relative correlated response, when selecting for FCR, is only 0.87 .

These calculations of FP were, however, based on a fixed set of economic assumptions. In practice these economic assumptions change over time. For instance, the feed price might increase or decrease while the carcass price remains the same, or vice versa. It is expected to have an influence on the ranking of the animals, based on their FP EBVs. It would also be of interest to determine which animals will be favored in rankings when these price ratios change one way or the other and what role an important trait such as feed efficiency will play in these rankings.

Figures 9, 10, and 11 present the feed, weaner and A3-carcass (carcass classification for animals younger than 2 years with between 3 and $5 \mathrm{~mm}$ of subcutaneous fat) prices from January 1998 to June 2002, respectively. 


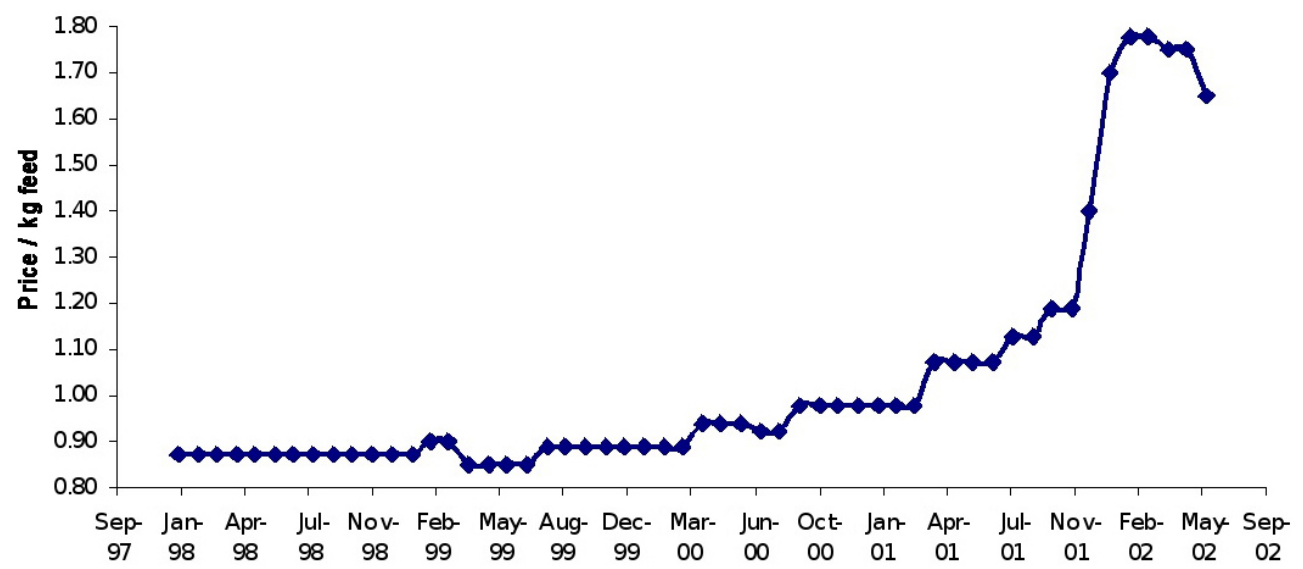

Figure 9. Feed prices for the Phase C feed ratio from January 1998 to June 2002.

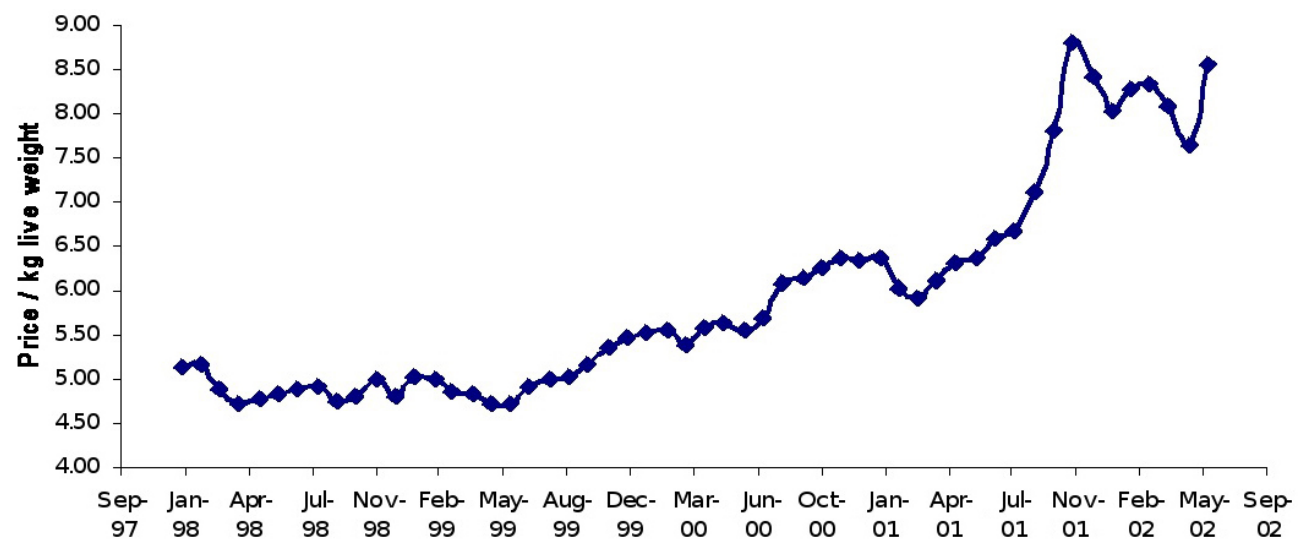

Figure 10. Weaner prices from January 1998 to June 2002 obtained from the South African Feedlot Association web page.

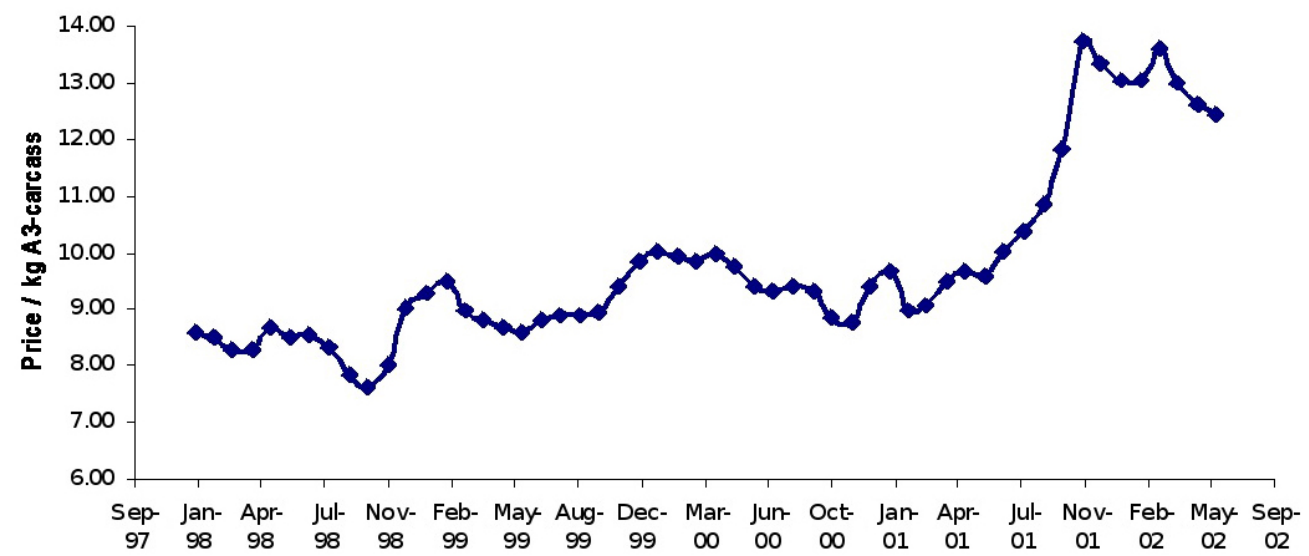

Figure 11. A3-carcass prices from January 1998 to June 2002. 
The centralized feed diet price increased gradually by R0.32 per kg from January $1998(\mathrm{R} 0.87 / \mathrm{kg})$ to November $2001(\mathrm{R} 1.19 / \mathrm{kg})$ where after it increased sharply by R0.59 to February 2002 (R1.78/kg) (Figure 9). Figures 10 and 11 show that the weaner and carcass prices increased from January 1998 to August 2001 by R1.52 and R1.82, respectively, where afterward the weaner and A3-carcass prices increased sharply by R2.14 and R3.36 per kg in the subsequent three months to reach a maximum in November 2001.

Figure 12 presents the A3-carcass feed price ratio as well as the weaner feed price ratio between January 1998 and May 2002. The best favorable economic environment to produce beef from the feedlot was in November 2001 (based on a positive feed margin) with a carcass price (A3) of 11.6 times that of the feed price and a weaner price of 7.40 times the feed price. This was due to the fact that the carcass and weaner price increased sharply after August 2001 while the feed price only responded a month later. The most unfavorable economic environment for beef production over the time of investigation was in May 2002 with a carcass and weaner price of 7.2 and 4.4 times that of the feed price, respectively. The average carcass/ feed and live weight weaner/feed price ratios over the time under investigation were 9.6 and 5.8 , respectively.

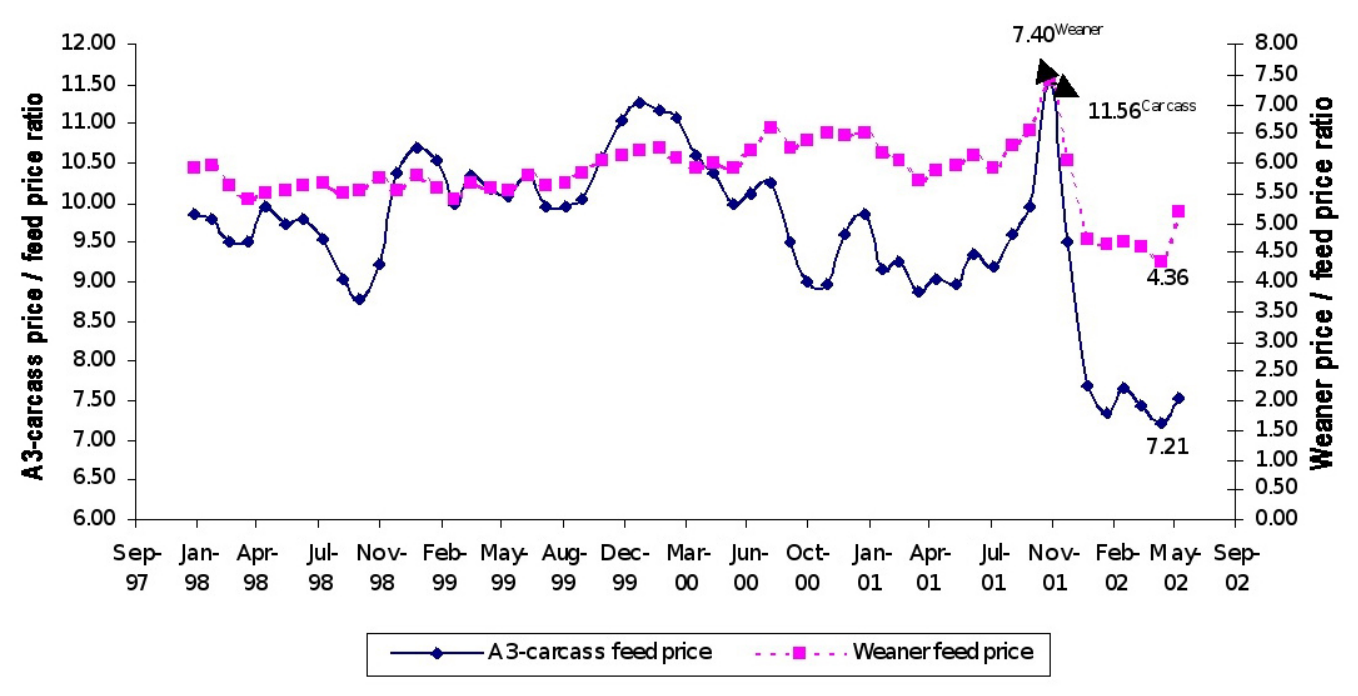

Figure 12. A3-carcass feed price and weaner feed price ratio from January 1998 to June 2002.

Table 6 presents the simple Pearson correlations between FP in the three different economic environments as mentioned above. From Table 6 it is apparent that there is no real difference between FPs in the three different environments as the lowest correlation of 0.90 between favorable and unfavorable economic environments (the two extreme environments) indicates. These different sets of FP values were then used to recalculate EBVs for each centralized tested bull in the different economic environments. Table 7 presents the Pearson (above the diagonal) and Spearman (below the diagonal) correlation between the EBVs of the three different sets of FP values. 
Table 6. Simple Pearson correlation between the feedlot profitability in the three different economic environments.

\begin{tabular}{lll}
\hline & AEE & UEE \\
\hline FEE & 0.97 & 0.90 \\
AEE & & 0.96 \\
\hline
\end{tabular}

$\overline{\mathrm{AEE}}=$ average economical environment; UEE $=$ unfavorable economic environment; FEE $=$ favorable economical environment.

Table 7. Pearson (above the diagonal) and Spearman (below the diagonal) correlation between the estimated breeding values of the three different sets of feedlot profitability.

\begin{tabular}{lccc}
\hline & FEE & AEE & UEE \\
\hline FEE & - & 0.99 & 0.90 \\
AEE & 0.99 & - & 0.95 \\
UEE & 0.89 & 0.92 & - \\
\hline
\end{tabular}

$\mathrm{AEE}=$ average economical environment $\mathrm{UEE}=$ unfavorable economic environment; $\mathrm{FEE}=$ favorable economical environment.

The high Pearson and Spearman correlations between EBVs derived for the different economic environments (Table 7) suggest that the average economic environment could be used to calculate EBVs for FP or feedlot growth profitability under varying feed/carcass price ratio scenarios. It is therefore not necessary to change the carcass, weaner or feed price on a regular basis to account for possible re-rankings based on FP EBVs.

\section{CONCLUSION}

The heritability estimate of FP indicates that this trait is genetically inherited and that it can be selected for.

The genetic correlation estimate of -0.92 between FCR and FP indicates that FP can be improved by selection for animals with a favorable feed conversion ratio.

It is possible to predict a feed intake value for performance-tested animals where animals were group fed with the help of a multiple regression equation.

The heritability, genetic correlation between other production and efficiency traits, and the genetic trend for FP suggested that FP should be considered as a selection criterion in any beef feedlot production system.

The high correlations obtained between EBVs for FP from different economic environments show that the average carcass, live weaner and feed prices over the last 54 months can be used as an indication of economic factors, and it is not necessary to change these factors on a regular basis.

However, carcass real time ultra-sound measurements are needed to predict feedlot profitability more accurately.

\section{REFERENCES}

Anonymous (1999). Beef Breeding in South Africa. Agricultural Research Council Animal Improvement Institute, Irene. Archer JA and Bergh L (2000). Duration of performance tests for growth rate, feed intake and feed efficiency in four 
biological types of beef cattle. Livest. Prod. Sci. 65: 47-55.

Arthur PF, Renand G and Krauss D (2001). Genetic parameters for growth and feed efficiency in weaner versus yearling Charolais bulls. Aust. J. Agric. Res. 52: 471-476.

Falconer DS and Mackay TFC (1996). Introduction to Quantitative Genetics. 4th edn. Weslay Longman Limited, Edinburgh Gate, Harlow, Essex.

Ferrell CL and Jenkins TG (1984). Energy utilization by mature, nonpregnant, nonlactating cows of different types. $J$. Anim Sci. 58: 234-243.

Groeneveld E (1994). VCE, a Multivariate Multimodel REML (co)Variance Component Estimation Package (22). In: Proceedings of the 5th World Congress on Genetics Applied to Livestock Production, Ghelph, Canada, 47-48.

Johnston D (2002). Genetic predictions of efficiency in the future: An Australian perspective. Proc. 34th Beef Improvement Federation Annual Meeting, Omaha. Available at [www.beefimprovement.org/proceedings.html].

Koots KR, Gibson JP, Smith C and Wilton JW (1994a). Analyses of published genetic parameter estimates for beef production traits. 1. Heritability. Anim. Breed. Abst. 62: 309-338.

Koots KR, Gibson JP and Wilton JW (1994b). Analyses of published genetic parameter estimate for beef production traits. 2. Phenotypic and genetic correlations. Anim. Breed. Abst. 62: 825-853.

SAS Institute (2000). SAS/STAT Users Guide, Version 8.02. SAS Institute, Cary.

Urick JJ, Pahnish OF, Richardson GV and Blackwell RL (1984). A comparison of crossbred and straightbred cow-calf pairs. I. Heterosis effects on total feed efficiency. J. Anim Sci. 58: 1151-1159.

Van Oijen M, Monato-Bumudez M and Nielsen M (1992). Economic efficiency of herds reserves of milking efficiency. Univ. of Nebraska, Beef Cattle Report, Lincoln. 